This newer view of Malthus and his significance is not one of those considered by Petersen. $\mathrm{He}$ is rather an indifferent guide to the demography of England in Malthusian times, and somewhat insensitive, so it seems to me, to the force of the progressive and Marxist critique of Malthusian thought. He rejects the view that the ecological crisis, which we are repeatedly told stares industrial society in the face, can properly be called Malthusian, just as he is sceptical of the views of the demographic catastrophists, as are other professional demographers.

Nevertheless it is understandable that the name of Malthus should have come to bulk so large in the learned world that at the end of this month a global meeting has been arranged to take place in Paris for the exposition and celebration of what that name has come to mean. Europeans, Western and Eastern; Africans, Asians and all the rest; those from developed and developing countries, Marxists and nonMarxists, will join together in debate about the Malthusian heritage. It can be said with confidence that he is of an intellectual standing to be worthy of such an occasion, and it is fortunate indeed that a work such as Petersen's should have appeared just in time to make that point absolutely evident.

Peter Laslett is Reader in Politics and the History of Social Structure at the University of Cambridge, UK, Fellow of Trinity College and Co-director of the Cambridge Group for the History of Population and Social Structure.

\section{Theory and practice in thermodynamics}

\section{F.L. Swinton}

Chemical Thermodynamics. By M.L. McGlashan. Pp.345. (Academic Press: London and New York, 1979.) £18, $\$ 41.50$.

THERE are very many bad textbooks of thermodynamics and very few that can be considered excellent. It is a not unexpected pleasure to be able to record that Professor McGlashan's new book joins such classics as Guggenheim's Thermodynamics (North-Holland: Amsterdam, 1967) and Prigogine and Defay's Chemical Thermodynamics (Longmans, Green: London, 1954) in this latter category. The present text is designed for teaching the subject up to and beyond British honours degree level and its coverage is thus more restricted than either of these two earlier works. It is more comparable in scope to books such as those by Denbigh (Principles of Chemical Equilibrium. Cambridge University Press: Cambridge, UK, 1966) and by Lewis, Randall, Pitzer and Brewer (Thermodynamics. McGraw-Hill: New York, 1961).

One original feature is the way in which, throughout the development of the subject, theory is closely wedded to experiment. There are two early chapters entitled "Practical Thermometry" and "Practical Calorimetry", and diagrams and descriptions of various pieces of apparatus used to measure thermodynamic properties are interspersed throughout the text. Whenever a new concept or function is introduced the reader is constantly being prompted to ask the question 'How do you measure it?' The author's contention is that only by asking and answering such a question can the reader build up a true appreciation of the practicalities of the subject.

While few will dispute the need to give prominence to both theory and experiment in a textbook designed to instruct readers who may have had little or no previous experience of thermodynamics, there are bound to be some who will question the wisdom of the author's strictly axiomatic theoretical development of the subject. For example, there must be very few presentday undergraduates who will accept on trust equation $(5.2 .1)$

$$
\mathrm{d} U^{\alpha}=T^{\alpha} \mathrm{d} S^{\alpha}-p^{\alpha} \mathrm{d} V^{\alpha}+\sum_{\mathrm{B}} \mu_{\mathrm{B}}^{\alpha} \mathrm{d} n_{\mathrm{B}}^{\alpha}
$$

that defines temperature, entropy and chemical potential for the first time and not question its origin. Once the axiomatic foundations are accepted, the author's subsequent derivations of all the standard thermodynamic relationships proceed with great clarity and rigour, and the university teacher as well as the undergraduate will learn much from a close perusal of the text. The treatment, in Chapters 11 and 12, of systems undergoing chemical reaction is particularly noteworthy.

One criticism that can be made of the book's subject matter is that the later, more advanced, chapters are heavily biased towards Professor McGlashan's own research interests, and whereas there are three separate chapters devoted to liquid mixtures, fluid mixtures and the principle of corresponding states, there are barely that number of pages concerned with solid-liquid equilibria. This detracts from the interest the book might otherwise have had for metallurgists and, to a lesser extent, for chemical engineers.

The book is superbly printed and produced, and one notable feature is the liberal use of footnotes. Most chapters conclude with a useful collection of numerical problems.

All university teachers will want to possess a personal copy immediately and I feel that it will not be long before McGlashan's Chemical Thermodynamics becomes established as a (or perhaps even the) standard teaching text in the subject.

F.L. Swinton is Professor of Chemistry at the New University of Ulster, Coleraine, Northern Ireland.

\section{Digital image processing}

\section{P.W. Hawkes}

Advances in Digital Image Processing. Edited by P. Stucki. Pp.332. (Plenum: New York and London, 1979.) \$23.63.

IN 1978, IBM (Germany) organized a conference on new developments in digital image processing, the proceedings of which are published here, offset from the authors' typescripts but with a number of colour plates tipped in. The book opens with two general papers, on evolution in image science by E. Klein and H.J. Metz and on trends in digital image processing research by T.S. Huang (whose volume, Picture Processing and Digital Filtering, has been reissued in paperback by Springer, with a short additional chapter and many new references). This chapter by Huang brings out clearly the difficulties of digital processing and indicates some of the ways in which they may be attacked. The remainder of the book is divided into theory, applications and implementations but has in fact a strongly applied flavour throughout, even the chapters on theory showing a marked engineering bias. Thus the first of these, by H.W. Schuessler, sets out from this author's Digitale Systeme zur Signalverarbeitung (Springer, 1973), and is addressed to readers with a background in electrical engineering. Still in the theory section, H.G. Musmann discusses digital coding of TV signals. Lastly, H. Niemann gives a formal and very well-organized account of digital image analysis, covering preprocessing, the extraction of picture constituents or primitives, including a discussion of textures, classification (in cytology, for example) and the important step of final analysis, including syntactical, graphical and relaxation methods.

The section on applications contains six chapters, on biomedical image processing (K. Preston), X-ray images (K.H. Hoehne, M. Boehm and G.C. Nicolae), Landsat (E.E. Triendl), document reproduction (P. Stucki), computer graphics (R. Williams) and industrial automation (L. Lieberman). Preston has quite recently written a very full account of digital picture analysis in cytology (in Digital Picture Analysis, edited by A. Rosenfeld: Springer, 1976), and the present chapter should be regarded as a supplement to that, interesting for its discussion of Golay logic. The remaining chapters in this section show why image processing is needed in the various fields considered.

The final section is devoted to implementation : distributed processing (W. Giloi), parallel processors (M. Duff), large-scale vector/array processors (G. Paul) and a low-cost system with new fast hardware (A. Peled). For many readers, 